\title{
Taide tekemisen prosessina
}

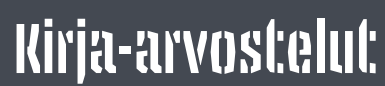

\section{Maarit Mäkelä}

Katve-Kaisa Kontturi, Ways of Following. Art, Materiality, Collaboration (London: Open humanities press, 2018), $268 \mathrm{~s}$.

Istun omakotitalon autotallin betonirampilla. Sen johon autolla ei voi ajaa, koska tontti on jaettu, eikä talon takana olevaa ulosmenotietä enää ole. Nïnpä autotalli palvelee säilytystilana ruuveille ja muttereille, saboille ja haroille, suksille ja pyörille - ja keramiikkauunille. Autotallista on kulku perunakellarïn, jonne olen arkistoinut näyttelyissä kiertäneitä teoksiani. Perunakellariin jobtavalla käytävällä on myös satoja kiloja suomalaista punasavea, kymmenen kilon kaksinkertaisiin muovipusseibin pakattuina. Työskentelin ohjaaja-valvojana kymmenkunta vuotta sitten brittiläisen kuvanveistäjän Anthony Gormleyn Clay and the Collective Body -projektissa Kaisaniemen puistoon viritetyssä kupla-hallissa, jossa kaupunkilaiset saivat muovata savesta mitä halusivat - keskellä Helsingin kevättalvea. Tekemisen lopputulemia ei poltettu, vaan projektin päätyttyä savea päätyi muun muassa paikallisten keraamikkojen varastoibin.

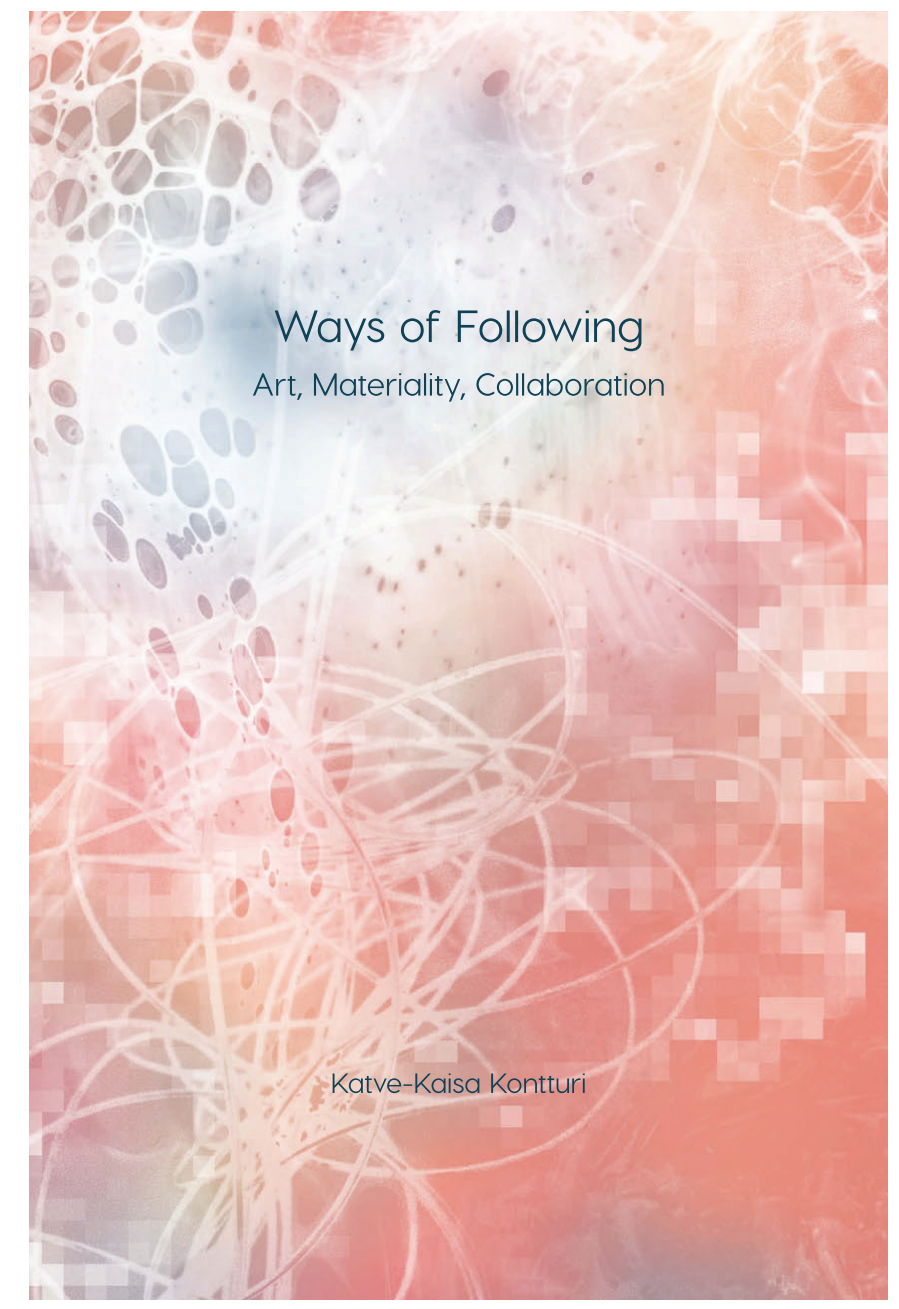


Olen levittänyt betonirampille paksun muovin, ja kantanut autotallista sen päälle kaksi pakettia savea. Pitelen kaksin käsin kiinni lekan varresta ja hakkaan kuivunutta savikimpaletta. fatkan hakkaamista kunnes kummatkin savikimpaleet ovat enintään peukalonpään kokoisina paakkuina. Laitan paakut saaviin ja kaadan päälle vettä sen verran, että savipaakut peittyvät. Seuraavana aamuna alan bitaasti rikkoa paljain käsin osittain jo veteen liuenneita savipaakkuja. Syntyneen savivellin nostelen kipsilevyn päälle tasaiseksi kerrokseksi ja odotan, että kipsiin imeytyy ylimääräinen kosteus. Muokkaan saven tasarakenteiseksi, pyörittelen sitä rytmisin kiertoliikkein. Pakkaan muokatun saven tiiviiisti muoviin ja jätän valtaosan työstämästäni savesta tekeytymään työhuoneeni lattialle. Kaulin pienestä savimäärästä kipsin päällä levyn, ja levystä leikkaan kabvikupin lautasta apuna käyttäen ympyrän tekeillä olevan ruukkuni pohjaksi.

Katve-Kaisa Kontturin kirjan Ways of Following. Art, Materiality, Collaboration keskiössä on taiteen tekemisen prosessi. Kontturi on ottanut tehtäväkseen seurata lukuisiin eri suuntiin polveilevaa teoksen syntyprosessia - prosessia, jossa sekä taiteilijalla että hänen käyttämillään materiaaleilla on aktiivinen rooli. Kyse on tapahtumasta, jossa erilaiset materiaalisuudet muodostavat eräänlaisen ennakoimattoman "yhdessä tulemisen". Seuraamalla taiteilijoita ja taideyleisöä, kirjoittaja saattaa lukijan tarkastelemaan taidetta tapahtumana, joka sisältää monimutkaisia tekemisen ja tuntemisen prosesseja. Kirjassa seurataan kolmen tai- teilijan prosesseja: Helena Hietasen, Susana Nevadon ja Marjukka Irnin. Vierailuista taiteilijoiden työhuoneilla kehräytyy ydinmetodi, joka avaa kirjoittajalle pääsyn luovan prosessiin. Kontturi on oivaltava kuuntelija ja katselija, joka ei ole tyytynyt vain tutkijan rooliin: hän on osallistunut tutkimiinsa taideprosesseihin toimimalla myös mallin ja kuraattorin rooleissa.

\section{Kolme taiteilijaa}

Kirjan eräänlaisena introna toimii Helena Hietasen teos Heaven Machine. Teosta kuvaillessaan Kontturi ottaa lukijaa kädestä kiinni ja vie hänet keskelle tekno-reivejä joissa minä ja muu maailma sekoittuvat ja kietoutuvat toisiinsa eri aistien ja liikkeen kautta "tanssin" aikana. Näin hän avaa lukijalle myös uuden horisontin liikkeestä, rytmistä, tilasta ja valosta rakentuvalle teokselle, joka pitää sisällään sekä videon että tilainstallaation. Hietasen ja Irnin teosten ympärille kehkeytyvä kerronta johdattelee lukijan mielenkiintoisesti teosten taustoihin ja syntyprosesseihin. Nevado on taiteilijoista kuitenkin se, jonka taideprosesseihin kirjoittaja on tutustunut syvällisimmin. Kontturi ymmärtää kirjansa "kokeiluna, jossa kirjoittaminen toimii välittäjänä taiteen kanssa, ja jossa kieltä käytetään sisäänpääsynä taiteen tekemisen maininkeihin" (10). Nevadon kohdalla mainingit vievät sekä kirjoittajan että lukijan mennessään. Aaltoihin heittäytyminen avaa uusia näkymiä taiteen tulemisen prosessiin, jossa erilaisen materiaali-

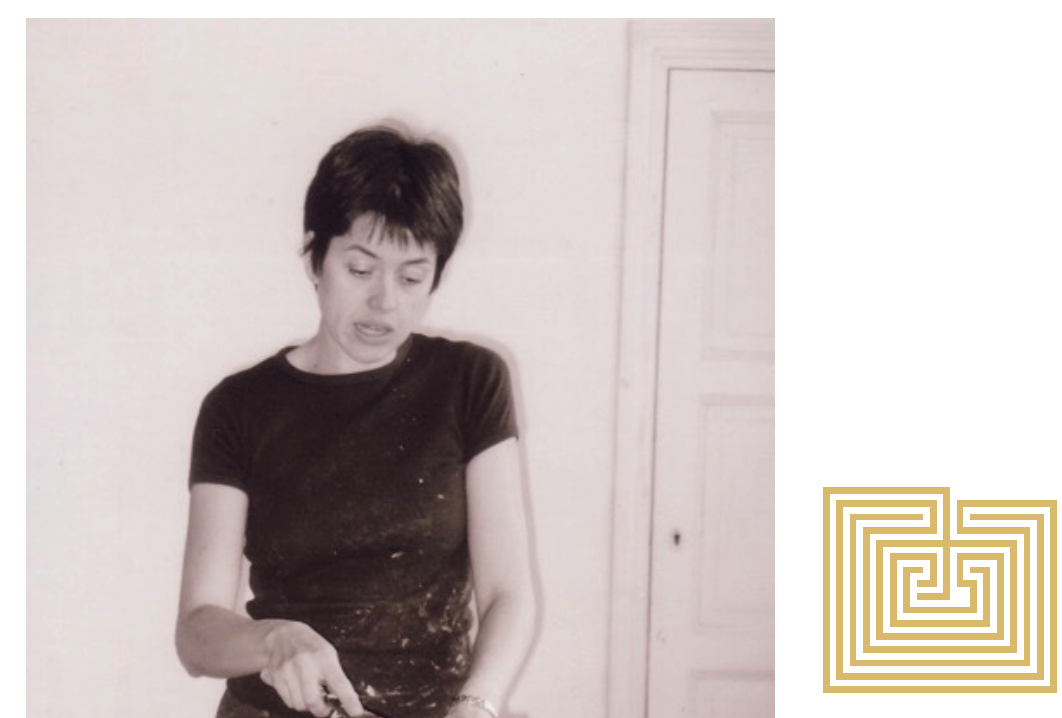

1. Susana Nevado ateljeellaan Turussa maaliskuussa 2004, jolloin hän valmisteli Room to Move -näyttelyä Titanik-galleriaan. Kuva: Katve-Kaisa Kontturi 
suudet, energiat ja ajatukset sekoittuvat, järjestäytyvät ja lopulta rauhoittuvat teokseksi.

Kontturin käsitys taideteoksesta palautuu taiteilija-teoreetikko Barbara Boltin ymmärrykseen, jossa keskeistä on ennen muuta taiteen tekeminen (work of art). ${ }^{1}$ Teoksen syntyyn vaikuttavat yhtä lailla muoto ja materia, sisältö ja ilmaisu, kuten myös inhimilliset ja ei-inhimilliset tekijät. Teoksen syntyprosessissa nämä tekijät yhdistyvät, risteytyvät ja linkittyvät eri tavoin. Kirjan ytimen muodostaa nähdäkseni kolmesta pääluvusta keskimmäinen ("Co-workings"), jossa Nevadon teosten "yhdessä tulemista" tarkastellaan juuri edellä mainittujen, toisiaan täydentävien näkökulmien kautta. Luvussa Kontturi avaa Nevadon taiteen syntyyn vaikuttavia tekijöitä reflektoiden työhuoneella näkemäänsä ja kokemaansa näitä teoreettisesti valaiseviin ja syventäviin teksteihin. Refleksiivisinä peilipintoina toimivat ennen muuta filosofi Gilles Deleuzen ja psykoanalyytikko Felix Guattarin kirjoitukset. Nevadon taideprosessi saa lisävaloa ja syvyyttä oivaltavasti nimetyissä alaluvuissa: Persoonattomat yhteydet ("Impersonal Connections"), Prosessin autonomisuus ("Autonomy of Process"), Käsityö ("Manual Labor") ja Taiteen ja elämän välissä ("Zigzagging Art and Life").

Alaluvussa Käsityö tarkastelussa on nimensä mukaisesti ruumiillinen työ ja käsin tekeminen. Luku korostaa käsityön merkitystä taideteoksen syntyyn johtavana tapahtumana. Uuden teoksen tekeminen

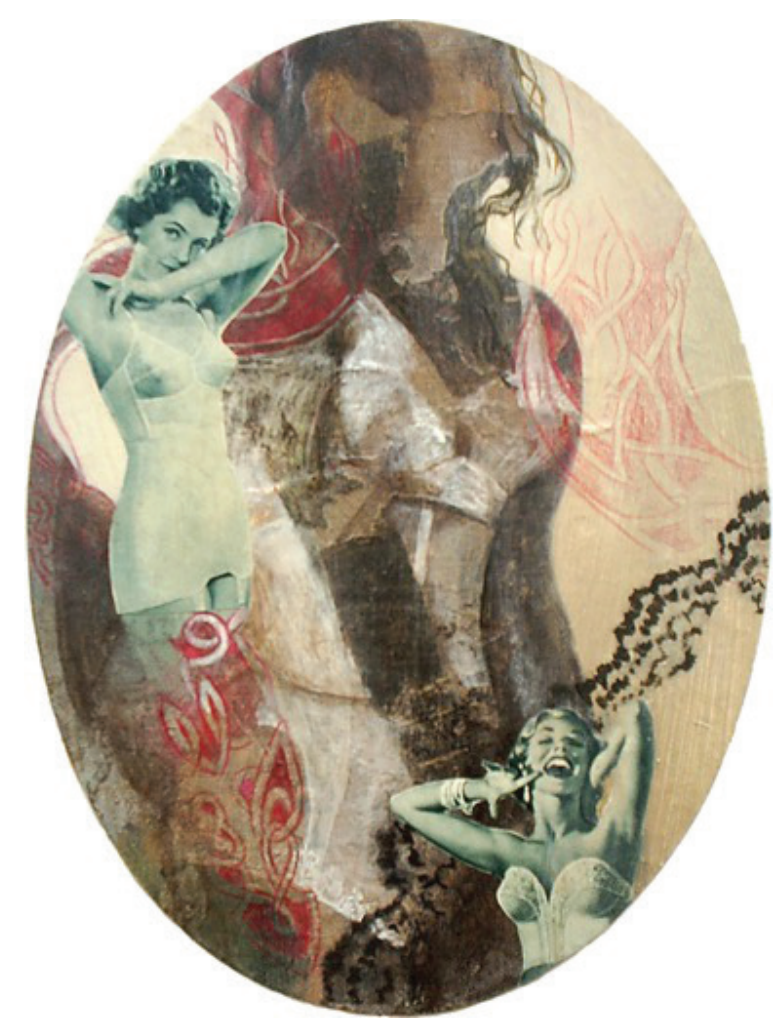

Kuvat 2 ja 3. Kaksoisnapamaalaus ja sen aiempi vaihe. Yksityiskohtia Susana Nevadon installaatiosta Rehellinen korteista ennustaja. Maalausprosessin dokumentoi Katve-Kaisa Kontturi Nevadon ateljeella keväällä 2005.

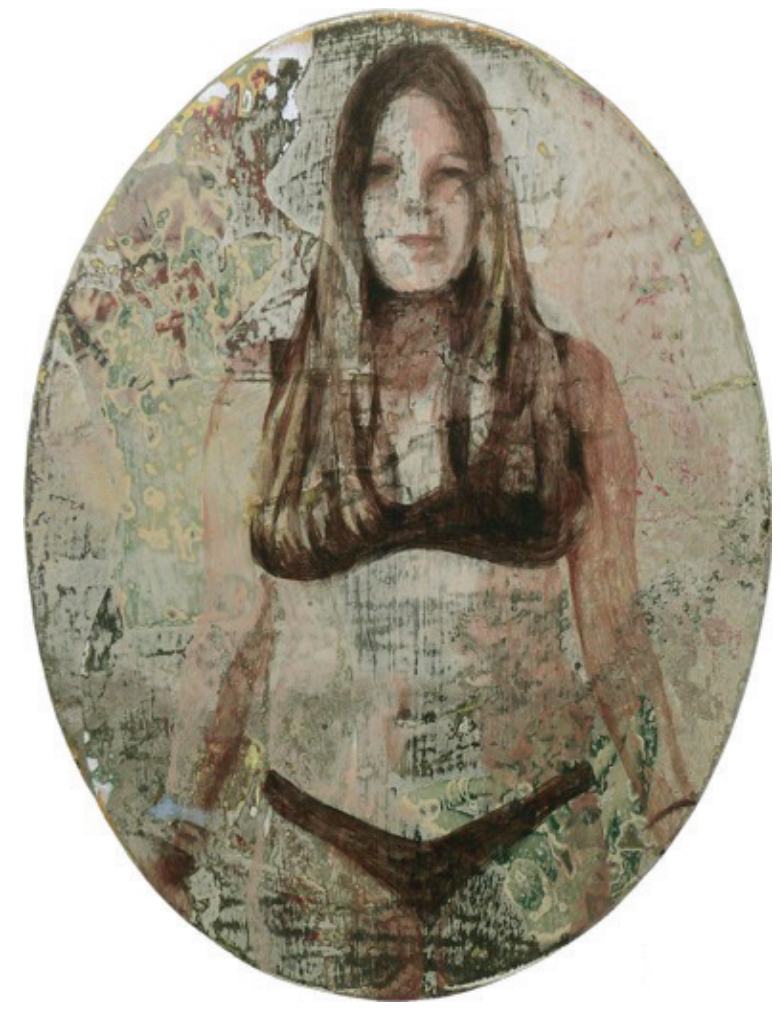


on manuaalista työtä, jota ei voi vain suorittaa, sillä jokainen vaihe vaatii tekijältään uniikkeja päätöksiä ja ratkaisuja. Välillä työn loppuun saattaminen - tai ylipäätään työn eteenpäin vieminen - on taistelua, sillä ei ole olemassa kaavaa tai ennalta toteutettavissa olevaa suunnitelmaa miten toteuttaa työ siten, että sen sisällölliset ja materiaaliset elementit asettuvat toistansa yhteyteen niin että lopputulemana on uusi, omalakinen teos. Kontturi avaa teokseen liittyviä sisällöllisiä ja materiaalisia ulottuvuuksia käyttämällä kerroksellisuuden (layer) käsitettä. Rakentaessaan teosta kerroksellisesti, taiteilija "kasaa, yhdistää ja muuntaa eri materiaaleja - eläviä, liikkuvia, esittäviä, semioottisia tai symbolisia - luodakseen kerrostamalla uusia rakennelmia, uutta elämää" (128).

\section{Luova prosessi ja sanallistamisen haaste}

Alaluvussa Prosessin autonomisuus kirjoittaja kuvailee osuvasti luovaa prosessia ja sitä, miten idea on muuntuvana läsnä läpi luovan prosessin - miten se kehkeytyy, muokkautuu ja elää osana tekemisen prosessissa. Työn aloittamiseen liittyvää konseptia tai lähtökohtaideaa ei kuitenkaan pohdita syvällisemmin. Mikä on idean merkitys sille, että työ ylipäätään lähtee liikkeelle, tulee tehdyksi? Luvun alussa Kontturi pohtii myös sitä, miten hankalaa tekijän on puhua luovasta prosessista, jonka kanssa parhaillaan työskentelee, ja sanoittaa asioita joille ei ole olemassa sanoja (s. 83).
Jäin pohtimaan, onko juuri taidehistorioitsijan tehtävänä olla perinteisesti se, joka analysoi prosessin rakennetta ja sanoittaa sen kulkua: kuvailee miten prosessi etenee ja mitä sen aikana tapahtuu?

Viimeisten vuosikymmenten aikana tähän tehtävään ovat tarttuneet yhä useammin myös itse tekijät. Taiteilijat ovat kautta aikojen sanoittaneet taiteen tekemiseen liittyvää ymmärrystään, viime aikoina yhä enenevässä määrin ennen muuta omaa taidettaan ja sen tekemiseen sitoutuneita prosesseja. ${ }^{2}$ Astumalla taiteilija-tutkijan kaksoisrooliin taiteilijat ovat ottaneet käyttöönsä analyyttisiä työkaluja joiden kautta avata luovaa prosessia sen sisältä käsin. Kirjan alussa Kontturi mainitsee myös tämän kehityksen (11), joka on edennyt taiteellisen tutkimuksen ja sille rinnakkaisten tutkimussuuntausten alla (esim. artistic research, practice-led research). Vielä toistaiseksi taiteilijat ovat hyödyntäneet kirjoituksissaan laajasti muiden alojen, kuten juuri taidehistorioitsijoiden, ajattelua ja löydöksiä. Kontturin kirjaa lukiessa ymmärrän, että on aika kierrättää ja risteyttää ajatuksia ja ideoita yhä vapaammin ja laajemmin molempiin suuntiin. Yhdistämällä kaksi näkökulmaa luovaan prosessiin - sen joka reflektoi prosessia sen sisäpuolelta ja sen, joka tarkastelee prosessia sen ulkopuolelta - saamme näkyviin entistä monitahoisemman ja tarkemman kuvan.

Kirjan viimeisessä luvussa kootaan kirjan anti yhteen siirtämällä fokus vielä kerran kuvallisesta ilmai-
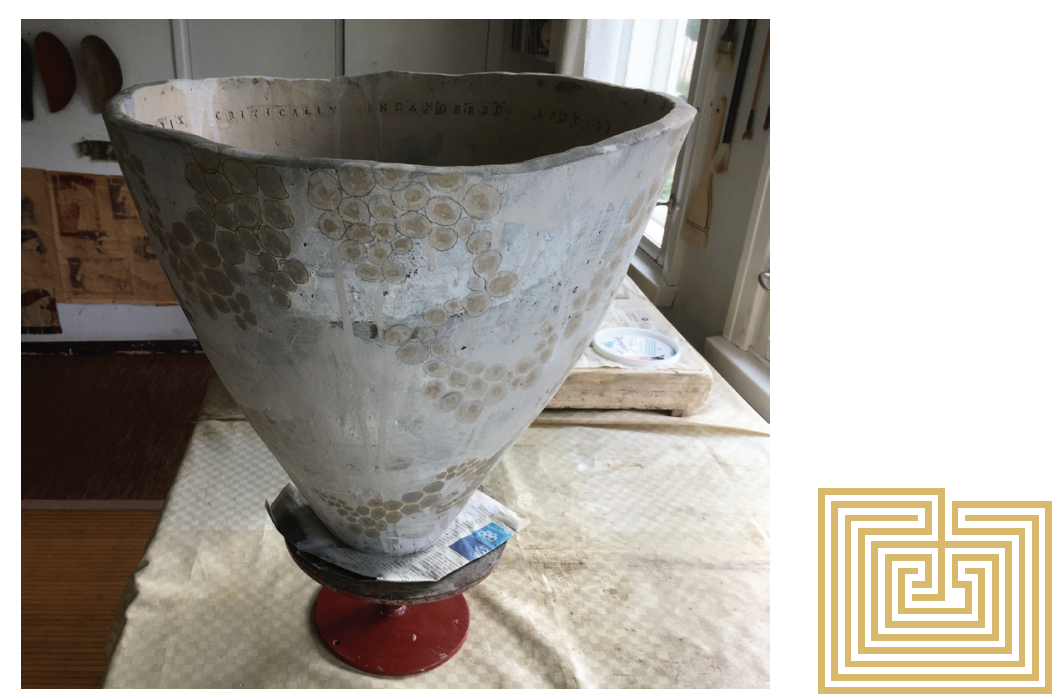

Kuva 4. Tekeillä oleva ruukku Acarospora Oligospora Maarit Mäkelän studiolla 7.9.2020. Ensimmäinen teos sarjasta Critically Endangered Species. Valokuva: Maarit Mäkelä. 
susta tekemisen prosessiin: miten tekijä ajattelee ja muokkaa sanomaansa osana kuvan tekemisen prosessia. Itse olen kutsunut tätä joidenkin muiden taiteilija-tutkijoiden tapaan materiaaliseksi ajatteluksi. Pohtimalla Helena Hietasen Becoming-Christ teosta Kontturi porautuu teoksen perimmäisten merkitysten äärelle ohittaen ilmeisimmät tulkinnat tästä teoksesta. Oikeastaan hän ohittaa keskustelun tekijän intentiosta, sillä hän ymmärtää että teokset syntyvät aina osana materiaalista prosessia jossa tekijän potentiaaliset intentiot ovat pikemminkin inspiraation lähteitä - lähtölaukauksia avoimelle, uudelle, kehkeytyvälle tekemisen prosessille.

Muokkaan savesta peukalonpaksuisen makkaran ja asettelen sen buolellisesti pyöreäksi leikkaamani savilevyn päälle. Painelen makkaran reunat kiinni sen alle asettamaani savilaattaan siten, että saan aikaiseksi astiamuodon. Fatkan muotoa vielä kabdella undella makkaralla, jonka jälkeen jätän sen lepäämään muovin alle. Lisään tekeillä olevaan ruukkuuni kolmen makkaran kerroksia kabdesta päivässä. Lopuksi tasoitan ruukun reunan ja levitän sen pinnoille leveällä siveltimellä savilietettä. Osa lietteestä jää valumaan pitkin pintaa jättäen valumat näkyväksi osaksi pinnan rakennetta. Seuraavaksi maalaan ruukun pintaan valitsemani kuvallisen teeman.

Luen Suomen Ympäristökeskuksen Punaista kirjaa vuodelta 2019. Kirjassa on luokiteltuna ja arvioituna 36604 eliölajia joista 489 äärimmäisen uhanalaisiksi. Osa näistä on lajeja - leviä, sammalia, putkilokasveja, kääväkkätä ja jäkäliä-joiden uhanalaisuus liittyy tavalla tai toisella maahan ja maankäyttöön, kuten rakentamiseen tai kaivannaistoimintaan. Ensimmäiseksi aibeekseni valikoituu suomukuoppajäkälä: sisäkkäinen pallorakenne ja kuvion (epä)rytminen toistuminen tarjoavat mielenkiintoisen lähtökohdan maalaukselle. Maalaan pallorakennetta kabdella Uudeltamaalta kaivetulta ja lietteeksi myllytetyllä maanäytteellä. Lisäksi käytän kabta muuta valmistamaani savilietettä, jotka sisältävät kotimaista punasavea, kaoliinia ja mangaania. Savelle tehty raakamaalaus näyttäytyy erilaisena kuin lopullinen maalaus. Lopulliset värit paljastuvat vasta poltossa, kun runkku munttuu keramiikaksi reilun 1000 asteen lämpötilassa. En tiedä kumpi maalauksista miellyttää minua enemmän.

\section{Viitteet}

$1 \mathrm{Ks}$. Barbara Bolt, Art Beyond Representation: The Performative Power of the Image (New York: I.B. Tauris, 2004).

2 Ks. esim. Maarit Mäkelä, Saveen piirtyviä muistoja. Subjektiivisen luomisprosessin ja sukupuolen representaatioita (Helsinki: Taideteollinen

Korkeakoulu, 2003); Tarja Pitkänen, Liian haurasta kuvaksi. Maalauksen aistillisuudesta. Helsinki: Like, 2006

TT Maarit Mäkelä toimii professorina Aalto-yliopiston Muotoilun laitoksella, jossa hän on uuden Contemporary Design -maisteriohjelman ja EMPIRICA-tutkimusryhmän johtaja. Hän on myös nykykeramiikan kentällä toimiva taiteilija. Väitöskirjassaan Saveen piirtyviä muistoja. Subjektiivisen luomisprosessin ja sukupuolen representaatioita (2003) hän tarkasteli omaa luovaa prosessiaan kolmen väitökseen liittyvän näyttelyn avulla. Teos johon Mäkelä arviossaan viittaa on parhaillaan esillä Designmuseon näyttelyssä Soil Matters.

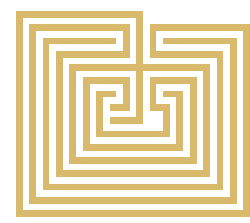

